\title{
Salmonella spp.: O ovo como veículo de transmissão e as implicações da resistência antimicrobiana para a saúde pública
}

\author{
Salmonella spp.: The egg as vehicle of transmission and the \\ implications of antimicrobial resistance for public health
}

\author{
Carla Rosane Paz Arruda Téo ${ }^{1 *}$, Tereza Cristina Rocha Moreira de Oliveira ${ }^{2}$
}

\section{Resumo}

A salmonelose é uma das doenças transmitidas por alimentos de maior prevalência, no Brasil e no mundo, apresentando um aumento acentuado e contínuo no número de casos relatados desde a década de 70. Os principais alimentos incriminados na veiculação de salmonelose são ovos e seus derivados, sendo que a manipulação desempenha um papel importante na disseminação da bactéria, por propiciar contaminação cruzada no ambiente de preparo de alimentos. No Estado do Paraná, o ovo aparece como o alimento incriminado na maior parte dos surtos de salmonelose desde 1993. Além disso, o emprego de antibióticos na produção animal, com objetivos profiláticos, terapêuticos e ou de promoção de crescimento, tem contribuído para a emergência de cepas de Salmonella resistentes a estes fármacos, o que pode dificultar o tratamento de infecções extra-intestinais causadas pela bactéria. Desta forma, este trabalho teve por objetivo revisar a contaminação de ovos e derivados por Salmonella spp. e as implicações da resistência antimicrobiana desta bactéria para a saúde pública.

Palavras-chave: Fatores intrínsecos e extrínsecos, contaminação cruzada, manipulação de alimentos

\begin{abstract}
Salmonelosis is one of the most prevalent foodborne diseases in Brazil and around the world, presenting a continuous and marked increase in the number of related cases since the 70's. The main foods associated to salmonelosis transmission are eggs and egg products, with handling practices playing an important role in bacterial dissemination by allowing cross contamination in the cooking surroundings. In Parana State, egg emerges as the food responsible for the most of outbreaks since 1993. Besides, the use of antibiotics for animal production, with profilatic, terapeutic or growth promotion objectives, have contributed to the emergence of resistant Salmonella strains, which may difficult the treatment of extraintestinal infections caused by the bacteria. Thus, this work aimed to review Salmonella contamination of eggs and egg products and the consequences of its antimicrobial resistance for public health.
\end{abstract}

Key words: Intrinsic and extrinsic parameters, cross contamination, food handling

1 Correspondências para Av. Gal. Osório, 55 D ap 102 - Ed. Tulipa Negra - Centro - Chapecó/SC - CEP 89802210 carlateo@brturbo.com.br

2 Universidade Estadual de Londrina - UEL - Centro de Ciências Agrárias - Departamento de Tecnologia de Alimentos e Medicamentos - Campus Universitário - Caixa Postal 6001 - Londrina - PR - tereza@uel.br

* Autor para correspondência.

Recebido para publicação 17/08/04 Aprovado em 15/04/05 


\section{Introdução}

A salmonelose apresenta-se, no Brasil e no mundo, como um desafio para a saúde pública. Apesar da subnotificação, a partir da década de 70 tem ocorrido um aumento acentuado e estável do número de casos vinculados a determinados sorotipos (BAIRD-PARKER, 1990; KAKU et al., 1995; SILVA; DUARTE, 2002), os quais variam geograficamente (UYTTENDAELE et al., 1998). Desta forma, Salmonella enterica subsp. enterica sorotipo Typhimurium ( $S$.Typhymurium), historicamente o mais associado com salmonelose em humanos e em aves, foi superado em muitos países por Salmonella enterica subsp. enterica sorotipo Enteritidis $(S$. Enteritidis), mais especificamente, pelo fagotipo 4 (PT4) (BARROW, 1990; FERNANDES et al., 2003; SANTOS et al., 2003).

Os alimentos mais implicados em surtos de salmonelose têm sido ovos e seus derivados e carne de aves, devendo ser destacada a manipulação inadequada como um fator de contaminação cruzada (KAKU et al., 1995; SAKAI; CHALERMCHAIKIT, 1996; CAMARGO et al., 1998; JAKABI et al., 1999; KIST; FREITAG, 2000; OLSEN et al., 2001).

O Brasil é o sétimo produtor mundial de ovos e o segundo de carne de frango, com uma produção anual de cerca de 15,4 bilhões de ovos (APA, 2005) e 8,5 milhões de toneladas de carne de frango (SESTI, 2005). Recentemente, tem sido observado, no Brasil, um aumento do consumo de ovos e carne de frango. Entre 1998 e 2005, o consumo per capita de ovos passou de 80 para 84 unidades (APA, 2005) e o de carne de frango de 22,9 para 35,0 Kg (MIELE; GIROTTO, 2005), tornando-se o Brasil o quinto consumidor de carne de frango no mundo (ABEF, 2005). Contribuem, para este aumento de consumo, mudanças nos hábitos alimentares e o fato destes alimentos serem fonte de proteína de alta qualidade a um custo relativamente baixo.

Dados epidemiológicos do Estado do Paraná indicam que, desde 1995, Salmonella tem sido o principal agente etiológico de surtos de doenças veiculadas por alimentos. Esses dados coincidem com o aumento gradativo do consumo dos alimentos mais implicados em surtos de salmonelose, não só no Brasil como em todo o mundo. Além disso, reforçando esta relação entre alimento e agente etiológico, aparece o ovo como alimento incriminado na maior parte dos surtos de salmonelose no Paraná, desde 1993 (CAMARGO, 2001).

O uso de antimicrobianos tem contribuído para a otimização da produção animal. Porém, esta prática desencadeia pressões seletivas que potencializam a emergência e a distribuição de cepas de Salmonella resistentes em carnes e outros produtos de origem animal, sendo as aves o principal reservatório de Salmonella resistente (TESSI et al., 1997). Como a maior parte das infecções humanas por Salmonella é decorrente da ingestão de alimentos de origem animal contaminados, o emprego de agentes antimicrobianos em animais destinados à alimentação humana é causa provável da emergência de cepas de Salmonella resistentes (ANGULO et al., 1999; SILVA; DUARTE, 2002).

O objetivo deste trabalho foi o de fazer uma revisão sobre a contaminação de ovos e derivados por Salmonella e sobre as implicações da resistência antimicrobiana desta bactéria para a Saúde Pública.

\section{Contaminação, sobrevivência e multiplicação de Salmonella em ovos in natura e derivados}

Entre os alimentos tidos como principais veículos de Salmonella estão os ovos e a carne de frango, sendo as aves consideradas o reservatório mais relevante desta bactéria (BAÚ et al., 1999; JAKABI et al., 1999; CHANG, 2000; KIST; FREITAG, 2000; LOOCK et al., 2000; MURAKAMI et al., 2001; OLSEN et al., 2001; PRAT et al., 2001; SILVA JR, 2001).

Diversos autores têm relatado que, em aves, o sorotipo Enteritidis pode ser transmitido verticalmente (transmissão transovariana), sugerindo uma adaptação da bactéria a estes hospedeiros. Entretanto, 
ovos podem ser, também, contaminados através do contato com o ambiente após a postura, ou no momento da postura, durante o trânsito pela cloaca, por deposição e subseqüente penetração do microrganismo através das estruturas da casca. Assim, devido à capacidade de transmissão vertical e horizontal, $S$. Enteridis tem se disseminado amplamente e persistido na indústria avícola (POPPE; DUNCAN; MAZZOCCO, 1998; KINDE et al., 2000; BERCHIERI JR et al., 2001; OKAMURA et al., 2001).

Pesquisas realizadas com ovos comerciais indicam que, geralmente, menos de 1,00\% dos mesmos estão contaminados com $S$. Enteridis e que, quando contaminados, o número de microrganismos é de cerca de 10 por ovo. Este tem sido o nível de contaminação encontrado, mesmo quando, experimentalmente, aves recebem inóculos de $10^{6} \mathrm{a}$ $10^{8} \mathrm{UFC} / \mathrm{mL}$ por via intravenosa e oral, respectivamente (GAST \& HOLT, 2000; KINDE et al., 2000). Porém, uma vez contaminados com $S$. Enteridis e expostos a temperaturas favoráveis à sua multiplicação, os ovos podem apresentar um grande número de bactérias por ocasião do consumo (CHANTARAPANONT et al., 2000).

Alguns fatores intrínsecos presentes nos ovos os protegem de uma maneira relativamente eficaz da transmissão horizontal ou vertical. Esta pode ser a explicação da baixa freqüência de contaminação e do pequeno número de microrganismos encontrados em ovos. Desta forma, a cutícula que recobre a casca, a própria casca e suas membranas funcionam como barreira mecânica eficiente contra a invasão de microrganismos (NASCIMENTO, 1992; JAY, 2000). Porém, as estruturas da casca são especialmente vulneráveis logo após a postura, ou seja, antes de ocorrer a secagem da cutícula (BERRANG et al., 1999). Esta vulnerabilidade pode ser reforçada pelos resultados obtidos por Miyamoto et al. (1998), que reportaram taxas de recuperação de Salmonella das membranas internas da casca e do conteúdo de ovos significativamente maiores quando os mesmos foram expostos à contaminação nas três primeiras horas após a postura.
A importância da cutícula como barreira foi, também, evidenciada por Fajardo et al. (1995), os quais relataram que ovos sem cutícula e com cascas experimentalmente inoculadas apresentaram uma contaminação interna posterior maior do que os que tinham cutícula. Além disso, foi observado que a penetração bacteriana não foi diretamente dependente dos poros. Da mesma forma, Nascimento, Cranstoun e Solomon (1992) não observaram uma relação direta entre o incremento do número de poros e uma maior invasão dos ovos por microrganismos, embora os poros da casca tenham seu número significativamente aumentado com o avanço etário da ave. Por outro lado, os autores encontraram uma relação entre anormalidades na formação da casca e a penetração de $S$. Enteridis. Portanto, a qualidade da casca determina uma maior ou menor dificuldade de deste sorotipo de Salmonella penetrar em ovos.

A presença de rachaduras, mesmo que microscópicas leva ao aumento da penetração de microrganismos. Inclusive, este fato tem sido observado em ovos submetidos a rápido resfriamento, o que parece aumentar o número e a extensão de rachaduras microscópicas na casca (FAJARDO et al., 1995). Condições que provocam o umedecimento da casca também favorecem a penetração bacteriana em ovos (FAJARDO et al., 1995; BERRANG et al., 1999; JAY, 2000; OLIVEIRA; SILVA, 2000).

Uma vez que a penetração através das estruturas da casca aconteça, os microrganismos encontram, na clara, outras barreiras à sua sobrevivência e multiplicação. A lisozima é uma proteína da clara capaz de lisar a parede bacteriana e tem ação, especialmente, contra bactérias Gram positivas. A avidina forma um complexo com a Biotina, tornandoa indisponível e dificultando a proliferação, principalmente das bactérias Gram negativas. A proteína ovoinibidor age inibindo proteases de fungos e de bactérias. A ovoflavoproteína é capaz de ligar Riboflavina (vitamina $\mathrm{B}_{2}$ ), tornando-a indisponível para os microrganismos e apresentando, por este motivo, ação antimicrobiana. A ovotransferrina, pela 
forte tendência de ligação ao ferro, indisponibiliza este mineral para os microrganismos (SGARBIERI, 1996; JAY, 2000). Especificamente com relação ao sorotipo Enteritidis, ovotransferrina é a principal substância inibidora presente no ovo (CHEN, H. et al., 2001; COGAN et al., 2001), além do fato de que a clara apresenta um conteúdo naturalmente baixo de ferro, de cerca de 0,4 mg/100 g (IBGE, 1999). O pH, que pode chegar a valores em torno de 9,0, faz com que a clara não represente ambiente favorável para a maioria dos microrganismos (SGARBIERI, 1996; JAY, 2000). Além disso, nesta faixa de $\mathrm{pH}$, há uma tendência mais forte de ligação do ferro a ovotransferrina e a remoção deste mineral pela enteroquelina (sideróforo produzido pelo sorotipo Enteritidis) é menos provável (COGAN et al., 2001).

O conjunto das características intrínsecas da clara inibe o crescimento de $S$. Enteridis quando a transmissão ocorre por via horizontal. Entretanto, quando o ferro chega à clara, vindo da gema, ou quando a bactéria penetra na gema, pelo enfraquecimento da membrana vitelina, a multiplicação ocorre rapidamente (HARA-KUDO et al., 2001). Segundo esses mesmos autores, o crescimento de $S$. Enteridis, inoculada na clara, nas proximidades da gema, foi detectado após 3 dias de incubação a $18^{\circ} \mathrm{C}$, tendo sido os ovos submetidos a envelhecimento artificial, prévio à inoculação, por 4 a 46 dias entre 10 e $30^{\circ} \mathrm{C}$. O crescimento observado foi maior e mais freqüente com o aumento das condições de tempo e temperatura empregadas para simular envelhecimento, indicando que mudanças na composição da clara, durante o armazenamento, diminuem a eficiência dos mecanismos de defesa.

Gast; Holt, 2000 e 2001 b relatam que a sobrevivência de Salmonella na clara é mais persistente em temperaturas superiores a $20^{\circ} \mathrm{C}$ do que naquelas em torno de $4^{\circ} \mathrm{C}$, sendo que, a $25^{\circ} \mathrm{C}$, a sobrevivência foi de 3 dias. Esta permanência da bactéria na clara, mesmo sem multiplicação, representa uma fonte de células viáveis que poderão iniciar rápido crescimento durante o armazenamento pela penetração na gema ou pela mistura dos conteúdos do ovo, por ocasião do seu consumo.
Mudanças que ocorrem no ovo, durante o armazenamento, estão relacionadas às trocas gasosas entre o alimento e o ambiente, realizadas através dos poros da casca. Desta forma, a clara perde água e dióxido de carbono, o que resulta em aumento do seu pH desde cerca de 7,6 até 9,7, em velocidade dependente da temperatura. Em decorrência, ocorre ruptura da estrutura de gel da clara e a membrana vitelina perde sua resistência, o que leva a gema a um estado fluido e a uma posição descentralizada, podendo a mesma entrar mais facilmente em contato com os demais conteúdos do ovo (FENNEMA, 1996; JAY, 2000).

Ovos com cascas menos espessas e com rachaduras apresentaram maior crescimento de $S$. Enteritidis na clara artificialmente contaminada, talvez pela aceleração das mudanças na composição da clara; além disso, alterações na membrana vitelina e na composição do ovo, como um todo, também podem afetar diretamente a habilidade da clara em facilitar ou inibir o crescimento de $S$. Enteritidis (HARAKUDO et al., 2001). Embora o pH da clara aumente a ligação do ferro à ovotransferrina, a sobrevivência de $S$. Enteritidis na clara ocorre e poderia ser explicada pela maior eficiência da enteroquelina em quelar ferro em relação à ovotransferrina, ou pela morte de microrganismos presentes na clara, que forneceriam ferro à $S$. Enteritidis (COGAN et al., 2001). Assim, embora a clara não seja um ambiente favorável para o crescimento de Salmonella, a bactéria pode não só sobreviver neste local, como, também, multiplicar-se (HARA-KUDO et al.,2001).

Como a clara, a gema é sítio potencial para a contaminação de ovos por Salmonella e, devido ao seu conteúdo em nutrientes, mesmo quando o sítio inicial de deposição da bactéria é externo à gema, o crescimento pode iniciar rapidamente (GAST; HOLT, 2000; GAST; HOLT, 2001a). A gema apresenta um ambiente mais favorável para a bactéria do que a clara, devido ao $\mathrm{pH}$ e ao conteúdo de lipídeos (CHANTARAPANONT et al., 2000). A gema fresca apresenta valores de $\mathrm{pH}$ em torno de 6,0, variando muito pouco, mesmo em condições de armazenamento prolongado (FENNEMA, 1996; JAY, 2000). 
As mudanças físicas e químicas na viscosidade da clara e na permeabilidade da membrana vitelina, exacerbadas pelo envelhecimento do ovo, permitem a migração da bactéria até a gema. A penetração na gema através da membrana vitelina, em ovos contaminados experimentalmente, é menor a $15^{\circ} \mathrm{C}$, mas ocorre após 24 horas a $25^{\circ} \mathrm{C}$. Uma vez na gema, Salmonella pode multiplicar, entre temperaturas de 10 a $25^{\circ} \mathrm{C}$, sendo que o número de bactérias aumenta rapidamente a $25^{\circ} \mathrm{C}$. Além disso, Salmonella pode estar naturalmente presente na gema, devido à transmissão vertical e, neste caso, a multiplicação é rápida em 24 horas a $25^{\circ} \mathrm{C}$. Embora a multiplicação na gema pareça ser bem menor quando a transmissão é horizontal, esta ocorre em níveis de risco ao consumidor (GAST; HOLT, 2000; GAST; HOLT, 2001a), o que demonstra a importância das rotas horizontal e vertical na contaminação de ovos por $S$. Enteritidis (COX; BERRANG; CASON, 2000).

Uma vez que o nível de $S$. Enteritidis no ovo é baixo (entre 10 e 20 células por ovo), mas que este número pode chegar a $10^{4}-10^{8} \mathrm{UFC}$ por ovo após 24 horas de armazenamento a $25^{\circ} \mathrm{C}$, uma das medidas práticas e efetivas para a redução dos riscos à saúde pública pode ser o controle do crescimento de $S$. Enteritidis durante o armazenamento (HARAKUDO et al., 2001; GAST; HOLT, 2001b).

O crescimento de Salmonella em ovos, após a postura, depende da temperatura de armazenamento, fato que ressalta a relevância deste fator extrínseco na prevenção do crescimento deste microrganismo. Ovos contaminados com $S$. Enteritidis e armazenados a $7^{\circ} \mathrm{C}$ por 7 dias não apresentaram aumento do nível de contaminação, ao contrário do observado em armazenamento a $25^{\circ} \mathrm{C}$ pelo mesmo período (HARAKUDO et al., 2001). Além disso, sendo baixa a temperatura no interior do ovo, a possibilidade de penetração do microrganismo na gema, onde o mesmo poderia multiplicar mais rapidamente, é reduzida. A dificuldade de penetração de Salmonella até a gema, através da clara, devido à temperatura de armazenamento, fornece uma margem de segurança até que a gema seja resfriada a $7^{\circ} \mathrm{C}$
(GAST; HOLT, 2001b). Portanto, fica evidente que o número de células de Salmonella no ovo, sua localização e o tempo de permanência do alimento em temperaturas favoráveis à multiplicação determinam diretamente os riscos a que serão expostos os consumidores (GAST; HOLT, 2000). Uma vez fornecidas condições para a multiplicação da bactéria no ovo, poderá haver sobrevivência a processamento térmico inadequado (CHANTARAPANONT et al., 2000), o que salienta a necessidade de fornecer informação também ao consumidor.

Neste contexto, as iniciativas de controle dos riscos potenciais oferecidos pelo consumo de ovos contaminados com Salmonella visam a cadeia produtiva na sua totalidade e chegam, inclusive, ao consumidor. Assim, surgem como medidas eficazes a pasteurização do ovo (na casca), o resfriamento rápido, o armazenamento sob refrigeração e em atmosfera modificada (com dióxido de carbono) e medidas educativas e informativas direcionadas ao consumidor, entre outras (TECHNOLOGIES target Salmonella in eggs, 2000).

O comportamento de Salmonella em alimentos, in natura ou elaborados, está condicionado aos diversos parâmetros intrínsecos e extrínsecos aos quais a bactéria é exposta ao contaminar o alimento. Contribui, também, para a atividade da bactéria, a presença de outros microrganismos, os quais podem manter relações de sinergismo ou antagonismo com Salmonella (JAY, 2000).

Com relação a alimentos elaborados, particularmente, alguns trabalhos têm evidenciado que obstáculos podem ser impostos à multiplicação de Salmonella. A sobrevivência de diversos patógenos, incluindo Salmonella, em produtos ácidos, como maionese, depende de uma variedade de parâmetros como temperatura, disponibilidade de oxigênio, acidez na fase aquosa, tipo de ácido utilizado, pH, tipo e quantidade de óleo empregado (SKANDAMIS; NYCHAS, 2000). PERALES; GARCÍA (1990) concluíram que a utilização de ácido acético na preparação de maionese, em quantidade suficiente 
para atingir um $\mathrm{pH}$ entre 3,6 e 4,0, praticamente elimina inóculos de Salmonella de $10^{6} \mathrm{UFC} / \mathrm{g}$ em 8 horas a $24^{\circ} \mathrm{C}$ e em 96 horas a $4^{\circ} \mathrm{C}$, o que indica que a baixa temperatura oferece proteção às células da bactéria contra o efeito bactericida do ácido. No mesmo estudo, os autores observaram que o ácido cítrico tem um efeito mínimo nas mesmas condições. Como a refrigeração parece proteger a bactéria contra os efeitos do acidulante, provavelmente devido a alterações na cinética da desnaturação protéica (SKANDAMIS \& NYCHAS, 2000), o controle de Salmonella nos ovos in natura, a fim de prevenir que a mesma atinja números de risco, ganha uma importância ainda maior.

Neste sentido, RADFORD; BOARD (1993) recomendam o uso de vinagre na preparação de maionese, uma vez que, na faixa de $\mathrm{pH}$ verificada neste alimento, o ácido acético apresenta maior número de moléculas não dissociadas do que o ácido cítrico. Além disso, sugerem adição de mostarda em concentração de 0,30 a $1,50 \%$ e de alho, devido ao efeito antimicrobiano do alil-isotiocianato e da alicina presentes nestes condimentos, respectivamente. A maior concentração de compostos fenólicos no azeite virgem de oliva justifica o seu uso, em relação ao óleo de girassol. Por outro lado, a adição de vegetais, como cenoura, resulta em absorção do ácido acético pelo vegetal e, conseqüentemente, em redução do efeito bactericida do mesmo.

O uso de óleos essenciais pode ser considerado um obstáculo adicional à sobrevivência e à multiplicação de Salmonella. Porém, o seu emprego em alimentos com finalidade de preservação é limitado, devido ao sabor e odor intensos que os mesmos conferem quando usados em doses eficazes. Óleo essencial de orégano (timol e isotimol), na concentração sensorialmente aceitável de $0,70 \%$, é uma alternativa natural que contribui para a segurança intrínseca de alimentos como a maionese, agindo sinergicamente com o baixo $\mathrm{pH}$ e com a temperatura de armazenamento (SKANDAMIS; NYCHAS, 2000).

\section{Disseminação de Salmonella pela manipulação dos alimentos}

SILVA JR (2001) afirma que existem quatro palavras fundamentais na prevenção de doenças transmitidas por alimentos: higiene, técnica, tempo e temperatura.

Diversos trabalhos têm evidenciado que procedimentos inadequados de manipulação contribuem para a disseminação de Salmonella no ambiente de preparo de alimentos, tendo sido essa bactéria recuperada de superfícies de fórmica até 24 horas após a contaminação (HUMPHREY; MARTIN; WHITEHEAD, 1994). Este fato é explicado pela capacidade de Salmonella aderir a diversas superfícies, como teflon, aço inoxidável e vidro, formando, nestas superfícies, um biofilme, em resposta ao estresse em termos de nutrientes e água disponíveis (AUSTIN et al., 1998; SOLANO et al., 1998; MATTICK et al., 2000b). Cepas de $S$. Enteritidis aderidas a estes materiais exibem uma resistência térmica aumentada, indicando que a eliminação desta bactéria aderida a pratos, copos e utensílios pode não ser tarefa simples (DOYLE; MAZZOTTA, 2000).

A presença de Salmonella em alimentos pode ocorrer pelo contato com superfícies contaminadas, situação que caracteriza a contaminação cruzada. Se a bactéria encontra nutrientes e condições adequadas, como pH, atividade de água e temperatura, poderá multiplicar-se rapidamente. Alimentos de origem animal, como ovos e carnes, são a principal fonte de microrganismos patogênicos que podem, por manipulação incorreta, contaminar de forma cruzada outros alimentos. Superfícies de trabalho, como pranchas para corte de alimentos, podem apresentar níveis de contaminação semelhantes aos da carne in natura (ZHAO et al., 1998).

COGAN; BLOOMFIELD; HUMPHREY (1999), em estudo sobre a contaminação cruzada por esta bactéria a partir de carcaças de frango, em uma cozinha domiciliar, demonstraram que as mãos dos 
manipuladores foram contaminadas e também diversas superfícies e utensílios, tais como a prancha para corte de alimentos, facas, maçanetas de portas, torneiras e, em menor freqüência, as toalhas para secagem de utensílios. Algumas superfícies permaneceram contaminadas mesmo após os procedimentos usuais de higienização, indicando que estes procedimentos, quando realizados de forma inadequada, podem contribuir em algum grau para a disseminação da bactéria no ambiente. Quando foram utilizadas toalhas para a higienização, as superfícies apresentaram menor contaminação antes do que após a limpeza. Estas observações salientam a importância da adoção de procedimentos de higienização adequados, com emprego de desinfetantes eficientes, durante o preparo de alimentos contaminados. Resultados semelhantes foram encontrados por Curtis; Franceschi; Castro (2000), em cozinhas industriais, utilizando como indicador o microrganismo E. coli.

Humphrey, Martin e Whitehead (1994) relatam que durante a elaboração de preparações à base de ovos artificialmente contaminados com Salmonella ocorreu ampla disseminação da bactéria entre os manipuladores (fato verificado pela análise de mãos), utensílios e superfícies de trabalho. Almeida et al. (1995) afirmam que, embora a adequada lavagem das mãos não garanta a eliminação de microrganismos, a redução dos níveis de contaminação ocorre após a higienização com sabão, antisséptico e água morna, pelo menos antes do início do trabalho, após a manipulação de alimentos crus e após o uso de sanitários. Chen, et al. (2001) apóiam esta afirmação, sugerindo que as mãos de manipuladores desempenham papel crucial na transferência de bactérias dos alimentos para as diversas superfícies de trabalho e vice-versa. Os autores afirmam, ainda, que as torneiras da cozinha são, também, uma significativa fonte de contaminação para as mãos.

Com relação às outras três palavras fundamentais na prevenção de toxinfecções alimentares (tempo, temperatura e técnica), é relevante analisar o aspecto tratamento térmico. Diversos tratamentos térmicos são utilizados em alimentos, tanto em nível industrial quanto doméstico, sendo que a maioria deles é eficiente na destruição dos patógenos. Entretanto, algumas características intrínsecas e extrínsecas, como $\mathrm{pH}$, atividade de água e temperatura de armazenamento, podem alterar a resistência de Salmonella ao calor. Assim, altas concentrações de sal ou de açúcar reduzem a atividade de água do alimento, desidratam parcialmente as células e aumentam sua resistência térmica. O mesmo acontece em alimentos ácidos, sendo que quando o ácido empregado é o acético, a resistência térmica de Salmonella é menor do que a observada com o uso dos ácidos láctico e cítrico (DOYLE; MAZZOTTA, 2000).

$\mathrm{O}$ armazenamento de alimentos em temperatura ambiente, antes do tratamento térmico, aumenta a resistência de Salmonella; porém, o armazenamento entre 4 e $8^{\circ} \mathrm{C}$ dificulta a sobrevivência da bactéria (DOYLE; MAZZOTTA, 2000). Nesta linha de investigação, Mattick et al. (2000a) salientam que a exposição de Salmonella a estresse subletal pode induzir a tolerância a condições mais extremas e que esta tolerância induzida pode, por sua vez, proteger a bactéria contra outras situações de estresse. Outras informações oferecem uma razão adicional que justifica a refrigeração de alimentos, sejam eles elaborados ou in natura, na prevenção da salmonelose. Entre elas está a afirmação de Mattick et al. (2000a) de que a exposição de $S$. Enteritidis a uma atividade de água de 0,95 em temperatura de $21^{\circ} \mathrm{C}$ aumenta a resistência térmica desta bactéria.

\section{Resistência Antimicrobiana de Salmonella: implicações para a saúde pública e a proposta de monitoramento}

Os antimicrobianos, atualmente, são empregados para fins terapêuticos e profiláticos em humanos e animais, além de serem adicionados às rações animais em doses subterapêuticas com o objetivo de melhorar seu crescimento e conversão alimentar. O emprego 
inadequado destes fármacos resulta na seleção e na conseqüente disseminação de cepas resistentes de vários microrganismos. Embora muitos dos problemas de resistência encontrados atualmente sejam resultantes do mau uso de antibióticos em humanos, existem evidências crescentes de que o uso de antibióticos na agropecuária esteja, há muito, contribuindo para esta questão (LOW, 1999). Uma variedade de antimicrobianos é usada na produção animal e o seu uso pode conduzir à seleção de cepas bacterianas resistentes, independentemente de seu emprego, seja ele terapêutico, profilático ou de promoção do crescimento (WHO, 1998), o que levou a Organização Mundial de Saúde a recomendar o controle e restrição de seu emprego na produção animal (WHO, 2001).

Para que um patógeno resistente tenha impacto na saúde pública é importante tanto o aspecto da transferência da resistência quanto o da disseminação dos microrganismos resistentes, o que ocorre após a colonização ou infecção do hospedeiro suscetível (ANGULO et al., 1999).

Embora as salmoneloses ocorram comumente em humanos, a transmissão direta de pessoa a pessoa não é comum e a maior parte das infecções é decorrente da ingestão de alimentos contaminados, principalmente os de origem animal. Desta forma, infecções causadas por Salmonella resistente a antimicrobianos parecem resultar, predominantemente, da ingestão de alimentos contaminados com cepas já resistentes (ANGULO et al., 1999); estas bactérias podem colonizar seu novo hospedeiro e transferir genes de resistência a bactérias presentes na microbiota do hospedeiro (MANIE et al., 1998). Assim, a causa mais provável para a emergência de cepas de Salmonella resistentes é o emprego de agentes antimicrobianos em animais destinados à alimentação humana (ANGULO et al., 1999).

A seleção de bactérias com resistência antimicrobiana natural e a aquisição de mecanismos de resistência por cepas inicialmente sensíveis têm contribuído para o aumento contínuo da prevalência de microrganismos resistentes. A emergência da resistência pode ser resultado inevitável do uso de antimicrobianos, mas há evidências de que isto ocorre com maior velocidade em algumas regiões do que em outras. A proporção de isolados humanos resistentes pode ser maior em países em desenvolvimento, indicando que as diferenças nas condições sanitárias e nos padrões de uso destes fármacos têm um papel importante. Há, também, o fato de que os microrganismos multirresistentes são selecionados com maior facilidade em ambientes hospitalares, particularmente em unidades de terapia intensiva, nas quais se empregam antibióticos de amplo espectro; por seleções sucessivas emergem microrganismos resistentes com escassas alternativas terapêuticas (ROSSI et al., 1999). Portanto, em países em desenvolvimento, indivíduos infectados podem ser fonte relevante de disseminação de Salmonella resistente, seja pela manipulação de alimentos, ou pela transmissão direta de pessoa a pessoa. Logo, o emprego de antimicrobianos para tratamento humano, nestes países principalmente, deve ser pautado por rigorosa cautela, já que pode desempenhar um papel tão importante na emergência da resistência antimicrobiana quanto o emprego na produção animal.

Assim, dada a utilidade de avaliar a correlação entre os agentes antimicrobianos empregados no tratamento humano de infecções causadas por Salmonella e a resistência antimicrobiana apresentada por isolados humanos, é conveniente observar alguns dados obtidos nos Estados Unidos, entre 1985 e 1995. A proporção de indivíduos com salmonelose tratados com ampicilina diminuiu de $60,00 \%$ em 1985 para $5,00 \%$ em 1995, enquanto a proporção de isolados humanos de Salmonella resistentes à ampicilina aumentou em uma taxa constante. Com relação a sulfametoxazol trimetoprim, a proporção de pacientes com salmonelose em tratamento com este agente foi constante, enquanto a resistência dos isolados humanos aumentou levemente. Já a proporção de 
pacientes com salmonelose recebendo tratamento com ciprofloxacina ou com cefalosporinas de amplo espectro aumentou consideravelmente, sem um aumento do número de isolados de Salmonella resistentes. Estes dados sugerem que existe baixa correlação entre os antimicrobianos empregados em humanos para tratamento de salmonelose e o desenvolvimento de resistência antimicrobiana, o que reforça a implicação dos alimentos, notadamente os de origem animal, na disseminação de Salmonella resistente (LEE et al., 1994; HERIKSTAD et al., 1997). Porém, segundo Rossi et al. (1999), esta relação pode ser um tanto diferente em países em desenvolvimento, onde o emprego de antimicrobianos em humanos pode estar, também, estreitamente relacionado à emergência da resistência.

A infecção humana por Salmonella em alguns casos pode ser severa e fatal, porém, a maior parte das infecções é gastrenterite não complicada, podendo a terapia com antibióticos prolongar o estado de portador e resultar em resistência antimicrobiana no indivíduo tratado (ANGULO et al., 1999). Entretanto, os agentes antimicrobianos são comumente prescritos para indivíduos com salmonelose que procuram atendimento médico (LEE et al., 1994). Em um estudo conduzido pelo Center for Disease Control and Prevention (CDC), em 1990 e 1995, 40,00\% dos indivíduos com salmonelose que buscaram atendimento médico receberam terapia com antibióticos. No Kenia, em 1997, 76,00\% das crianças com gastroenterite que tiveram atendimento médico, independentemente do agente causal, receberam terapia com agentes antimicrobianos (SHAPIRO et al., 2001).

Por outro lado, em contraste com o recomendado para gastrenterites não complicadas, os antimicrobianos são essenciais para o tratamento de indivíduos com bacteremia, meningite, ou outra infecção extra-intestinal causada por Salmonella (ANGULO et al., 1999). Entretanto, a escolha de agentes antimicrobianos para o tratamento de infecções sistêmicas tem ficado restrita a um grupo cada vez menor de drogas, devido à crescente resistência antimicrobiana de Salmonella observada em amostras de origem não intestinal, usualmente do sangue (LEE et al., 1994). Nos Estados Unidos, $21,00 \%$ dos isolados humanos, selecionados ao acaso em 1996, apresentaram resistência à ampicilina, $10,00 \%$ ao cloranfenicol e $4,00 \%$ a sulfametoxazol trimetoprim. Em contraste, praticamente todos os isolados de Salmonella, neste estudo, foram sensíveis às fluoroquinolonas e às cefalosporinas de terceira geração (HERIKSTAD et al., 1997). Por esta razão e por causa das propriedades farmacodinâmicas destes antimicrobianos, as fluoroquinolonas e as cefalosporinas de terceira geração são as drogas de escolha para o tratamento de infecções sistêmicas causadas por Salmonella em adultos e crianças, respectivamente (ANGULO et al., 1999). Estas informações salientam a necessidade de monitoramento contínuo da resistência antimicrobiana com relação aos fármacos de escolha para tratamento humano, tanto entre isolados humanos quanto naqueles provenientes de amostras de rações, de animais e de ambiente de produção e processamento de animais para alimentação humana.

Um estudo realizado na Argentina, entre 1993 e 1995, com isolados de Salmonella obtidos de carcaças de frango, indicou que $52,70 \%$ dos mesmos foi resistente à tetraciclina e $21,50 \%$ à ampicilina, com nenhuma resistência sendo observada à gentamicina e à cefalotina. Outro trabalho realizado na Argentina, entre 1995 e 1996, com isolados humanos, mostrou que a maioria era sensível aos antimicrobianos testados; porém, $46,00 \%$ dos isolados obtidos em hospitais pediátricos foi resistente à ampicilina, 40,00\% foi resistente às cefalosporinas de terceira geração e 33,00\% foi resistente à sulfametoxazol - trimetoprim. Nesse caso, a característica de resistência foi notadamente mais intensa em isolados de origem pediátrica e foi detectada alta taxa de resistência às cefalosporinas de terceira geração (ROSSI et al., 1999), drogas de escolha, segundo Angulo et al. (1999), para o tratamento de infecções causadas por Salmonella 
em crianças. Estes dados reforçam que o uso de antibióticos em humanos também tem papel importante na disseminação da resistência antimicrobiana.

Neste sentido, muitos pesquisadores têm, também, relatado o direto relacionamento entre o consumo de fluoroquinolonas e a emergência de microrganismos quinolona-resistentes (LOW, 1999). Este dado é importante pelo fato de que estas são, segundo Angulo et al. (1999), as drogas de escolha para o tratamento de infecções por Salmonella em adultos. A relação entre o uso de antibióticos e a resistência antimicrobiana não é sempre clara. Por exemplo, o monitoramento da resistência de enterobactérias à estreptomicina, em um hospital do Canadá, em 1991, mostrou que, após 20 anos de suspensão do uso deste agente antimicrobiano, mais de $20,00 \%$ dos isolados humanos permaneciam resistentes (LOW, 1999). Portanto, uma vez que a resistência a um agente antimicrobiano emergiu, reduzir seu uso pode não eliminar ou reduzir a resistência.

Por outro lado, trabalho realizado em Taiwan, entre 1989 e 1993, com isolados humanos de Salmonella, mostrou que a resistência à ampicilina, cloranfenicol e sulfametoxazol - trimetoprim, inicialmente alta, apresentou uma tendência à reversão, com a substituição desses antimicrobianos pelas quinolonas e cefalosporinas de terceira geração. A possibilidade de que esta relação seja verdadeira e direta é reforçada pelo fato de que uma aparente emergência da resistência a estes fármacos mais modernos foi observada. Os pesquisadores concluem que a introdução de novos agentes antimicrobianos, tanto em humanos quanto em animais, tem mudado o perfil epidemiológico da resistência aos antimicrobianos e que a seleção de antibióticos para uso humano e veterinário deve ser feita com cautela, paralelamente ao monitoramento da resistência (SU et al., 2001).

$\mathrm{Na}$ Grécia, pesquisadores observaram um aumento de isolados de $S$. Enteritidis resistentes a antimicrobianos entre 1987 e 1993. Isolados de fontes humanas foram, em geral, menos resistentes à ampicilina e às sulfonamidas do que os de outras origens, sendo que os isolados de origem animal foram mais resistentes do que os oriundos de rações. Neste país, foi, também, observado que a introdução de medidas restritivas ao uso de antibiótico na produção animal coincidiu com a estabilidade da resistência de $S$. Enteritidis aos antimicrobianos. Outro fato que fornece evidência da ligação entre o uso de antimicrobianos na produção animal e a prevalência da resistência é a observação de que os isolados de origem animal foram os mais resistentes e que esta resistência foi contra, justamente, os agentes antimicrobianos mais usados na produção animal (TASSIOS et al., 1997).

Trabalho desenvolvido na África do Sul, com isolados de Salmonella obtidos de carcaças de frango, demonstrou que uma grande parte da flora bacteriana de produtos de frango frescos foi resistente a uma variedade de antimicrobianos testados. A resistência à tetraciclina e à estreptomicina foi atribuída ao uso destes fármacos na avicultura em doses subterapêuticas, o que pode ter selecionado cepas resistentes (MANIE et al., 1998).

Por outro lado, pesquisa realizada em Hong-Kong, com isolados de $S$. Enteritidis obtidos de origem humana indicou que todos os isolados foram sensíveis às cefalosporinas de terceira geração, às fluoroquinolonas e ao cloranfenicol; um isolado foi resistente à ampicilina e à cefalotina, um foi resistente à tetraciclina e dois a sulfametoxazol - trimetoprim (LING et al., 1998). Comparados com as informações de outros países, estes dados representam uma baixa resistência antimicrobiana de Salmonella. Na Colômbia, por exemplo, entre 1997 e 1999, foi encontrada uma taxa de $55,50 \%$ de resistência entre isolados humanos de Salmonella, com $22,40 \%$ de multiresistência. Os maiores índices de resistência foram, justamente, para tetraciclina $(32,50 \%)$, ampicilina (26,00\%), sulfametoxazol - trimetoprim $(23,80 \%)$, cloranfenicol $(3,90 \%)$, cefotaxima $(2,00 \%)$ e gentamicina $(1,40 \%)$, com todos os isolados sendo sensíveis à ciprofloxacina (MUÑOZ et al., 2000). 
No Brasil, diversos trabalhos têm investigado a resistência de Salmonella a antimicrobianos. Peresi et al. (1999) observaram que $13,79 \%$ dos isolados de Salmonella obtidos de carcaças de frango comercializadas em São Paulo, entre 1995 e 1996, foram resistentes a um ou mais dos antimicrobianos testados. Dentre os sorotipos isolados, $S$. Enteritidis apresentou resistência a mais de um antibiótico, o que tem implicações epidemiológicas consideráveis em saúde pública, dada a prevalência deste sorotipo nas infecções humanas.

Fonseca et al. (2001) encontraram, no Rio de Janeiro, uma freqüência de multiresistência em $S$. Infantis de fonte humana da ordem de 68,60\%. Outro estudo realizado no mesmo Estado, com isolados de Salmonella de origem animal e de rações, encontrou uma taxa de $22,74 \%$ de resistência, com predomínio das amostras de origem animal (70,00\%) (REZENDE et al., 2001). Por outro lado, Gasparetto (2000), analisando 28 cepas isoladas de carcaças de frango comercializadas na Região de Londrina-PR, encontrou $3,57 \%$ de resistência à ampicilina e cefoxitina e $64,28 \%$ de resistência intermediária, principalmente frente à tetraciclina. Já um estudo realizado no Instituto Oswaldo Cruz, avaliando, no ano de 2000, isolados de Salmonella de amostras de origem humana, alimentar, animal, ambiental e de matérias-primas de diversas regiões do país, encontrou $36,40 \%$ de isolados resistentes a, pelo menos, um antibiótico (COSTA et al., 2001). Porém, Peresi et al. (1998), avaliando cepas de Salmonella isoladas de alimentos e de pacientes envolvidos em surtos ocorridos na Região Noroeste do Estado de São Paulo, entre 1993 e 1997, encontraram sensibilidade da maior parte dos isolados a todos os antibióticos testados.

Castro et al. (2002), estudando a questão da resistência, avaliaram 1138 cepas de Salmonella de origem humana coletadas entre 1985 e 1999 em Ribeirão Preto-SP e relataram que a resistência da bactéria aos agentes antimicrobianos usualmente empregados no tratamento da diarréia infecciosa foi baixa, exceção feita à tetraciclina, droga para a qual foi observado o maior percentual de resistência (média de 35,0\%). Os autores afirmam, ainda, que a droga mais eficaz, neste trabalho, foi o ácido nalidíxico.

Já Fernandes et al. (2003) avaliaram 105 cepas de $S$. Enteritidis de origem humana (fezes, sangue e urina) e não humana (alimentos à base de ovos implicados em surtos de salmonelose, amostras de frango e de dejetos), isoladas no período de 1975 a 1995 no Estado de São Paulo, concluindo que 66,7\% das cepas foram sensíveis aos agentes antimicrobianos testados, com as cepas resistentes a uma única droga $(24,8 \%)$ sendo originadas majoritariamente de material humano e as multirresistentes $(8,5 \%)$ de pacientes hospitalizados. Com base nestas observações, os autores afirmam que, a despeito da baixa incidência de resistência observada, parece ser crucial um ativo monitoramento da resistência antimicrobiana de Salmonella, especialmente Enteritidis, pelas implicações para a saúde pública de uma potencial disseminação de clones resistentes.

Outros trabalhos realizados no Brasil têm chegado a conclusões semelhantes, ou seja, a resistência tem sido principalmente observada em cepas de origem humana e a multirresistência em cepas originadas de pacientes hospitalizados (FERNANDES et al., 1999; TAVECHIO et al., 1999). A partir destas observações, SILVA; DUARTE (2002) sugeriram que os genes da resistência possam estar associados à virulência ou, pelo menos, que o fato de as cepas humanas apresentarem um perfil de resistência mais elevado do que aquele encontrado nas cepas nãohumanas, no Brasil, torna a situação ainda mais preocupante do ponto de vista da saúde pública.

O número de viagens internacionais e a intensificação das relações comerciais entre os mais diversos países têm aumentado enormemente nos últimos anos, resultando na multiplicação de oportunidades para microrganismos resistentes serem carreados rapidamente de um lugar para outro (HAKANEN et al. 2001). As informações sobre a resistência, quando disponíveis, não têm sido 
traduzidas em ações efetivas para a saúde pública, tendo ficado restritas a um pequeno círculo de profissionais, pesquisadores e estudiosos do assunto. Este fato tem resultado em ações locais e em publicações, pouco acrescentando ao entendimento do impacto da resistência em termos de taxas de morbi-mortalidade e de custos em saúde. Existe, portanto, a partir do conhecimento da incidência, da prevalência e das conseqüências da resistência antimicrobiana, a necessidade de ações práticas para a saúde pública, a curto e médio prazos. Ou seja, o fluxo desta informação precisa ser implementado, uma vez que a resistência antimicrobiana é um problema global, o qual requer respostas locais, nacionais e globais. A investigação epidemiológica é a chave para o entendimento da magnitude e das tendências da resistência, a partir do qual poderão ser estabelecidas medidas de intervenção, as quais poderão ter seu impacto avaliado (WILLIAMS, 2001).

Desta forma, a fim de rastrear a emergência da resistência antimicrobiana, foi criado o Sistema Nacional de Monitoramento de Resistência Antimicrobiana Para Enterobactérias (NARMS National Antimicrobial Resistance Monitoring System - Enteric Bacteria), nos Estados Unidos. Neste sistema, Salmonella foi escolhido como o microrganismo sentinela entre os isolados humanos. Os objetivos do NARMS são: a) fornecer dados sobre a extensão e as tendências temporais da resistência antimicrobiana em Salmonella e outros microrganismos entéricos, b) detectar rapidamente o surgimento da resistência, c) oferecer informação oportuna a médicos e médicos veterinários, d) prolongar a empregabilidade, no tratamento humano, de drogas aprovadas pela promoção do uso judicioso e prudente dos antimicrobianos, e) identificar áreas para investigações mais detalhadas. As informações resultantes deste programa de monitoramento e da investigação de surtos serão distribuídas, oportunamente, a veterinários, médicos e a associações de produtores animais. O uso destas informações, em curto prazo, permitirá o redirecionamento do uso destas drogas, a fim de diminuir a transmissão e a disseminação da resistência (FEDORKA-CRAY et al., 1999).

De forma geral, agências internacionais têm, recentemente, recomendado e incentivado o desenvolvimento de programas de monitoramento da resistência antimicrobiana tanto em isolados de origem humana quanto animal. Salmonella tem sido adotado como microrganismo indicador para estudos de resistência devido às suas características de ubiqüidade e de importante agente causador de zoonose (USERA et al., 2002).

\section{Considerações finais}

Atualmente, é de consenso geral o risco potencial que o ovo pode representar para a saúde pública, tendo em vista sua implicação em casos esporádicos e em surtos de salmonelose (CAMARGO, 2001, SILVA; DUARTE, 2002). Alguns fatores intensificam este risco, tais como o armazenamento de ovos sob temperatura ambiente, a possibilidade de disseminação de cepas bacterianas resistentes a antibióticos pelo emprego destes fármacos na produção animal e a desinformação do consumidor, em termos de armazenamento e técnicas seguras de preparo dos alimentos.

Este contexto pode conduzir a recomendações equivocadas, visando evitar ou reduzir o consumo de ovos pela população. Porém, sendo este um alimento fonte de ferro e de proteína de alta qualidade e dado o seu custo razoavelmente baixo, antes de recomendar sua exclusão da dieta, é imperativa a adoção de estratégias que tornem seu consumo seguro. Assim, ações educativas direcionadas à população em geral e o estabelecimento, por parte de órgãos governamentais, de um sistema de monitoramento da resistência antimicrobiana podem ser medidas eficientes para a redução do risco oferecido, atualmente, pelo consumo deste alimento. Além disso, o armazenamento sob temperatura ambiente é aspecto que precisa ser revisto pela Agência Nacional de Vigilância Sanitária, ao menos 
Salmonella spp.: o ovo como veículo de transmissão e as implicações da resistência antimicrobiana para a saúde pública

na esfera de comercialização, o que minimizaria as possibilidades da ocorrência de níveis de contaminação de ovos por Salmonella spp. capazes de causar doença.

\section{Referências bibliográficas}

ABEF - ASSOCIAÇÃO BRASILEIRA DE EXPORTADORES DE FRANGO. Consultado na INTERNET, em 22 de abril de 2005. Disponível em http:// www.abef.com.br/.

ALMEIDA, R. C. C. et al. Avaliação e controle da qualidade microbiológica de mãos de manipuladores de alimentos. Revista de Saúde Pública, v. 29, n. 4, p. 290-294, 1995.

ANGULO, F. J. et al. Significance and sources of antimicrobial-resistant nontyphoidal Salmonella infections in humans in the United States: the need for prudent use of antimicrobial agents, including restricted use of fluoroquinolones, in food animals. In: AGRICULTURE'S ROLE IN MANAGING ANTIMICROBIAL RESISTANCE CONFERENCE, 1999, Canada. In. ANNALS OF THE AGRICULTURE'S ROLE IN MANAGING ANTIMICROBIAL RESISTANCE CONFERENCE, Canada, 1999, p. 14-28.

APA - ASSOCIAÇÃO PAULISTA DE AVICULTURA. Estatísticas. Consultado na INTERNET, em 30 de março de 2005. Disponível em http://www.apa.com.br/ estatisticas/prmundfrg.

AUSTIN, J. W. et al. Thin aggregative fimbriae enhance Salmonella Enteritidis biofilm formation. FEMS Microbiology Letters, v. 162, p. 295-301, 1998.

BAIRD-PARKER, A. C. Foodborne illness: foodborne salmonellosis. The Lancet, v. 336, p. 1231-1235, nov. 1990.

BARROW, P. Salmonella Enteritidis vaccine research. Poultry International, dec. 1990.

BAÚ, A. C.; ALEIXO, J. A. G.; CARVALHAL, J. B. Ocorrência de Salmonella spp. em produtos de frangos comercializados em Pelotas. In: CONGRESSO BRASILEIRODEHIGIENISTAS DE ALIMENTOS , 5, 1999, Foz do Iguaçu. Anais do $5^{\circ}$ Congresso Brasileiro de Higienistas de Alimentos, Foz do Iguaçu, 1999.

BERCHIERI JR, A. et al. Further studies on vertical transmission and persistence of Salmonella enterica serovar Enteritidis phage type 4 in chickens. Avian Pathology, v. 30, p. 297-310, 2001.

BERRANG, M. E. et al. Eggshell membrane structure and penetration by Salmonella Typhimurium. Journal of Food Protection, v. 62, n. 1, p. 73-76, 1999.
CAMARGO, N. J. et al. Surtos de 1978 a 1997. Curitiba: Secretaria de Saúde do Estado do Paraná, Centro de Saneamento e Vigilância Sanitária, 1998.

CAMARGO, N. J. Avaliação dos surtos de toxinfecção alimentar - Paraná - 1978 a 1999. In: SILVA JR, E. A. Manual de controle higiênico-sanitário em alimentos. 4.ed. São Paulo: Livraria Varela, 2001. p. 357-365.

CASTRO, F. A. et al. Prevalence and antimicrobial resistance of Salmonella serotypes in patients from Ribeirão Preto, São Paulo, Brazil, between 1985 and 1999. The Brazilian Journal of Infectious Diseases, v. 6, n. 5, p. 244-251, 2002.

CHANG, Y. H. Prevalence of Salmonella spp. in poultry broilers and shell eggs in Korea. Journal of Food Protection, v. 63, n. 5, p. 655-658, 2000.

CHANTARAPANONT, W. et al. Factors influencing inactivation of Salmonella Enteritidis in hard-cooked eggs. Journal of Food Protection, v. 63, n. 1, p. 36-43, 2000.

CHEN, H. et al. Optimization of iron supplementation for enhanced detection of Salmonella Enteritidis in eggs. Journal of Food Protection, v. 64, n. 9, p. 1279-1285, 2001.

CHEN, Y. et al. Quantification and variability analysis of bacterial cross-contamination rates in common food service tasks. Journal of Food Protection, v. 64, n. 1, p. 72-80, 2001.

COGAN, T. A. et al. Growth of Salmonella Enteritidis in artificially contaminated eggs: the effects of inoculum size and suspending media. International Journal of Food Microbiology, v. 70, p. 131-141, 2001.

COGAN, T. A.; BLOOMFIELD, S. F.; HUMPHREY, T. J. The effectiveness of hygiene procedures for prevention of cross-contamination from chicken carcasses in the domestic kitchen. Letters in Applied Microbiology, v. 29, p. 354-358, 1999.

COSTA, R. G. et al. Monitoramento da resistencia antimicrobiana em Salmonella sp. caracterizadas no Laboratório de Enterobactérias (LABENT)/Centro de Referência Nacional de Cólera e Outras Enteroinfecções Bacterianas (CRNCEB). In: SIMPÓSIO DE RESISTÊNCIA BACTERIANA AOS ANTIMICROBIANOS, 1, 2001, Rio de Janeiro. Anais do $1^{\circ}$ Simpósio de Resistência Bacteriana aos Antimicrobianos, Rio de Janeiro, 2001, p. 72.

COX, N. A.; BERRANG, M. E.; CASON, J. A. Salmonella penetration of egg shells and proliferation in broiler hatching eggs - a review. Poultry Science, v. 79, p. 15711574,2000 .

CURTIS, M. L.; FRANCESCHI, O.; CASTRO, N. Determinación de la calidad microbiológica de alimentos servidos em comedores de empresas privadas. Archivos Latinoamericanos de Nutrición, v. 50 n. 2, 2000. 
DOYLE, M. E.; MAZZOTTA, A. S. Review of studies on the thermal resistance of Salmonellae. Journal of Food Protection, v. 63, n. 6, p. 779, 795, 2000.

FAJARDO, T. A. et al. Penetration of Salmonella Enteritidis into eggs subjected to rapid cooling. Journal of Food Protection, v. 58, n. 5, p. 473-477, 1995.

FEDORKA-CRAY, P. J. et al. NARMS-EB veterinary isolates 1998 summary. In: AGRICULTURE'S ROLE IN MANAGING ANTIMICROBIAL RESISTANCE CONFERENCE, 1999, Canada. Annals of the Agriculture's Role In Managing Antimicrobial Resistance Conference, Canada, 1999, p. 205-207.

FENNEMA, O. R. Food chemistry. New York: Marcel Dekker, 1996.

FERNANDES, S. A. et al. Caracterização de cepas de Salmonella enteritidis isoladas de crianças internadas em hospitais do município de São Paulo.In: CONGRESSO BRASILEIRO DE MICROBIOLOGIA, 1999, Brasil. Anais do Congresso Brasileiro de Microbiologia, Salvador, Bahia, Brasil, 1999, p. 86.

FERNANDES, S. A. et al. Phenotypic and molecular characterization of Salmonella Enteritidis strains isolated in São Paulo, Brazil. Rev. Inst. Med. Trop. S. Paulo, v. 45, n. 2, p. 59-63, 2003.

FONSECA, E. L. et al. Avaliação epidemiológica e molecular da resistência aos antimicrobianos em cepas de Salmonella Infantis. In: SIMPÓSIO DE RESISTÊNCIA BACTERIANA AOS ANTIMICROBIANOS, 1, 2001, Rio de Janeiro. Anais do $1^{\circ}$ Simpósio de Resistência Bacteriana aos Antimicrobianos, Rio de Janeiro, 2001, p. 33.

GASPARETTO, K. M. P. O. Salmonella spp.: isolamento em carcaças de frango e estudo de fatores de virulência. Londrina, 2000. 90 f. Dissertação de Mestrado em Ciência de Alimentos. Departamento de Tecnologia de Alimentos e Medicamentos, Universidade Estadual de Londrina.

GAST, R. K.; HOLT, P. S. Influence of the level and location of contamination on the multiplication of Salmonella Enteritidis at different storage temperatures in experimentally inoculated eggs. Poultry Science, v. 79, p. $559-563,2000$

GAST, R. K.; HOLT, P. S. Assessing the frequency and consequences of Salmonella Enteritidis deposition on the egg yolk membrane. Poultry Science, v. 80, p. 9971002, 2001a.

GAST, R. K.; HOLT, P. S. Multiplication in egg yolk and survival in egg albumen of Salmonella enterica serotype Enteritidis strains of phage types 4, 8, 13a and 14b. Journal of Food Protection, v. 64, n. 6, p. 865-868, 2001 b.

HARA-KUDO, Y. et al. Laying season and egg shell cracks on the growth of Salmonella Enteritidis in the egg albumen during storage. Journal of Food Protection, v. 64, n. 8, p. 1134-1137, 2001.

HERIKSTAD, H. et al. Emerging quinolone-resistantSalmonella in the United States. Emerging Infectious Disease, v. 24, suppl. 1, p. 136, 1997.

HUMPHREY, T. J.; MARTIN, K. W.; WHITEHEAD, A. Contamination of hands and work surfaces with Salmonella Enteritidis PT4 during the preparation of egg dishes. Epidemiology and Infection, v. 113, p. 403-409, 1994.

IBGE - INSTITUTO BRASILEIRO DE GEOGRAFIA E ESTATÍSTICA. Tabelas de composição de alimentos. In: Estudo Nacional da Despesa Familiar. 5.ed. Rio de Janeiro: IBGE, 1999.

JAKABI, M. et al. Observações laboratoriais sobre surtos alimentares de Salmonella spp. ocorridos na Grande São Paulo, no período de 1994 a 1997. Revista do Instituto Adolfo Lutz, v. 58, n. 1, p. 47-51, 1999.

JAY, J. M. Modern food microbiology. 6.ed. Maryland: Aspen. 2000

KAKU, M. et al. Surto alimentar por Salmonella Enteritidis no Noroeste do Estado de São Paulo, Brasil. Revista de Saúde Pública, v. 29, nº. 2, p. 127-131. 1995.

KINDE, H. et al. Pathologic and bacteriologic findings in 27-week-old comercial laying hens experimentally infected with Salmonella Enteritidis, phage type 4. Avian Diseases, v. 44, p. 239-248, 2000.

KIST, M. J.; FREITAG, S. Serovar specific risk factors and clinical features of Salmonella enterica spp. enterica serovar Enteritidis: a study in South-West Germany. Epidemiology and Infection, v. 124, p. 383-392, 2000.

LEE, L. A. et al. Increase in antimicrobial-resistant Salmonella infections in the United States, 1989-1990. Journal of Infectious Diseases, v. 170, p. 128, 1994.

LING, J. M. et al. Antimicrobial susceptibilities and molecular epidemiology of Salmonella enterica serotype Enteritidis strains isolated in Hong Kong from 1986 to 1996. Journal of Clinical Microbiology, v. 36, n. 6, p. 1693-1699, 1998.

LOOCK, F. V. et al. Analysis of foodborne disease in Belgium in 1997. Acta Clinica Belgica, v. 55, n. 6, p. 300306,2000 .

LOW, D. E. What is the issue of antimicrobial resistance? In: AGRICULTURE'S ROLE IN MANAGING ANTIMICROBIAL RESISTANCE CONFERENCE, 1999, Canada. Annals of the Agriculture's Role In Managing Antimicrobial Resistance Conference, Canada, 1999, p. 211 . 
MANIE, T. et al. Antimicrobial resistance of bacteria isolated from slaughtered and retail chickens in South Africa. Letters in Applied Microbiology, v. 26, p. 253-258, 1998.

MATTICK, K. L. et al. Habituation of Salmonella spp. at reduced water activity and its effect on heat tolerance. Applied and Environmental Microbiology, v. 66, n. 11, p. 4921-4925, nov. 2000a.

MATTICK, K. L. et al. Survival and filamentation of Salmonella enterica serovar Enteritidis PT4 and Salmonella enterica serovar Typhimurium DT104 at low water activity. Applied and Environmental Microbiology, v. 66, n. 4, p. 1274-1279, apr. 2000b.

MIELE, M.; GIROTTO, A. F. Embrapa: análise da situação atual e perspectiva da avicultura de corte. Ave World, v. 3, n. 14, p. 16-20, fev/mar.2005.

MIYAMOTO, T. et al. Salmonella penetration through eggshell associated with freshness of laid eggs and refrigeration. Journal of Food Protection, v. 61, n. 3, p. 350-353, 1998.

MUÑOZ, N. et al. Vigilancia en red de los serotipos y la susceptibilidad antimicrobiana de Salmonella spp., Shigella spp. y Vibrio cholerae O1, 1997-1999. Biomédica, v. 20, p. 210-217, 2000.

MURAKAMI, K. et al. Environmental survey of Salmonella and comparison of genotypic character with human isolates in Western Japan. Epidemiology and Infection, v. 126, p. 159-171, 2001.

NASCIMENTO, V. P.; CRANSTOUN, S.; SOLOMON, S. E. Relationship between shell structure and movement of Salmonella Enteritidis across the eggshell wall. British Poultry Science, v. 33, p. 37-48,1992.

NASCIMENTO, V. P. Eggshell quality and microbial penetration. Poultry International, may 1992.

OKAMURA, M. et al. Differences among six Salmonella serovars in abilities to colonize reproductive organs and to contaminate eggs in laying hens. Avian Diseases, v. 45, p. 61-69, 2001.

OLIVEIRA, D. D.; SILVA, E. N. Salmonela em ovos comerciais: ocorrência, condições de armazenamento e desinfecção da casca. Arquivos Brasileiros de Medicina Veterinária e Zootecnia, v. 52, n. 6, p. 1-9, 2000.

OLSEN, S. J. et al. The changing epidemiology of Salmonella: trends in serotypes isolated from humans in the United States, 1987-1997. The Journal of Infectious Diseases, v. 183, p. 753-761, 2001.

PERALES, I.; GARCÍA, M. I. The influence of $\mathrm{pH}$ and temperature on the behaviour of Salmonella Enteritidis phage type 4 in home-made mayonnaise. Letters in Applied Microbiology, v. 10, p. 19-22, 1990.
PERESI, J. T. M. et al. Surtos de enfermidades transmitidas por alimentos causados por Salmonella Enteritidis. Revista de Saúde Pública, v. 32, n. 5, p. 1-12, out. 1998.

POPPE, C.; DUNCAN, C. L.; MAZZOCCO, A. Salmonella contamination of hatching and table eggs: a comparison. Canadian Journal of Veterinarian Research, v. 62, p. 191-198, 1998.

PRAT, S. et al. Tipificación fágica de Salmonella Enteritidis de muestras clínicas, alimentarias y avícolas en Chile. Revista Panamericana de Salud Publica, v. 9, n. 1, p. 7-12, 2001.

RADFORD, S. A.; BOARD, R. G. Review: fate of pathogens in home-made mayonnaise and related products. Food Microbiology, v. 10, p. 269-278, 1993.

REZENDE, A. F. et al. Resistência antimicrobiana em Salmonella sp. isoladas de fonte animal e sua repercussão na cadeia alimentar. In: SIMPÓSIO DE RESISTÊNCIA BACTERIANA AOS ANTIMICROBIANOS, 1, 2001, Rio de Janeiro. Anais do $1^{\circ}$ Simpósio de Resistência Bacteriana aos Antimicrobianos, Rio de Janeiro, 2001, p. 54.

ROSSI, A. et al. Vigilancia de la resistencia a los antibacterianos en Argentina. Programa WHONET, 19951996. Revista Panamericana de Salud Publica, v. 6, n. 4, p. 234-241, 1999.

SAKAI, T.; CHALERMCHAIKIT, T. The major sources of Salmonella Enteritidis in Thailand. International Journal of Food Microbiology, v. 31, p. 173-180, 1996.

SANTOS, L. R. et al. Phagetypes of Salmonella Enteritidis isolated from clinical and food samples, and from broiler carcasses in southern Brazil. Rev. Inst. Med. Trop. S. Paulo, v. 45, n. 1, p. 1-4, 2003.

SESTI, L. FACTA: aviculture de corte brasileira 2004. Ave World, v. 3, n. 14, p. 58-62, fev/mar. 2005.

SGARBIERI, V. C. Proteinas em alimentos protéicos. São Paulo: Livraria Varela. 1996.

SHAPIRO, R. L. et al. Antimicrobial-resistant bacterial diarrhea in rural Western Kenya. The Journal of Infectious Diseases, v. 183, p. 1701-1704, 2001.

SILVA, E. N.; DUARTE, A. Salmonella Enteritidis em aves: restrospectiva no Brasil. Revista Brasileira de Ciência Avícola, v. 4, n. 2, p. 1-4, 2002.

SILVA JR, E. A. Manual de controle higiênico-sanitário em alimentos. 4.ed. São Paulo: Livraria Varela, 2001.

SKANDAMIS, P. N.; NYCHAS, G. J. E. Development and evaluation of a model predicting the survival of Escherichia coli O157:H7 NCTC 12900 in homemade eggplant salad at various temperatures, $\mathrm{pHs}$, and oregano essential oil concentrations. Applied and Environmental Microbiology, v. 66, n. 4, p. 1646-1653, apr. 2000. 
SOLANO, C. et al. Discrimination of strains of Salmonella Enteritidis with differing levels of virulence by an in vitro glass adherence test. Journal of Clinical Microbiology, v. 36, n. 3, p. 674-678, mar. 1998.

$\mathrm{SU}, \mathrm{L} . \mathrm{H}$. et al. Secular trends in incidence and antimicrobial resistanse among clinical isolates of Salmonella at a university hospital in Taiwan, 1983-1999. Epidemiology and Infection, v. 127, p. 207-213, 2001.

TASSIOS, P. T. et al. Molecular epidemiology of antibiotic resistance of Salmonella Enteritidis during a 7-year period in Greece. Journal of Clinical Microbiology, v. 35, n. 6, jun. 1997.

TAVECHIO, A. T. et al. Resistência antimicrobiana de sorotipos de Salmonella isolados no estado de São Paulo no período de 1996 a 1999.In: CONGRESSO BRASILEIRO DE MICROBIOLOGIA, 1999, Brasil. Anais do Congresso Brasileiro de Microbiologia, Salvador, Bahia, Brasil, 1999, p. 86.

TECHNOLOGIES target Salmonella in eggs. Food Engineering, jul/aug. 2000.

TESSI, M. A. et al. Drug resistance of Enterobacteriaceae isolated from chicken carcasses. Journal of Food Protection, v. 60, n. 8, p. 1001-1005, 1997.
USERA, M. A. et al. Antibiotic resistance of Salmonella spp. from animal sources in Spain in 1996 and 2000. Journal of Food Protection, v. 65, n. 5, p. 768-773, 2002.

UYTTENDAELE, M. R. et al. Prevalence of Salmonella in poultry carcasses and their products in Belgium. International Journal of Food Microbiology, v. 40, p. 18, 1998.

WHO - WORLD HEALTH ORGANIZATION. Use of quinolones in food animals and potential impact on human health. Report of a WHO Meeting. Geneva, Switzerland, jun. 1998.

WHO - WORLD HEALTH ORGANIZATION. WHO consultation on the monitoring of antimicrobial usage in food animals for the protection of human health. Oslo, Norway, 2001.

WILLIAMS, R. Globalization of antimicrobial resistance: epidemiological challenges. Clinical Infectious Diseases, v. 33, suppl. 3, p. 116-117, 2001.

ZHAO, P. et al. Development of a model for evaluation of microbial cross-contamination in the kitchen. Journal of Food Protection, v. 61, n. 8, p. 960-963, 1998. 